\title{
ANALISA MODEL HIDROGRAF BANJIR KALI NGOTOK DEN- GAN METODE SCS, SNYDER DAN NAKAYASU
}

\author{
Gilang Id'fi
}

\begin{abstract}
Abstrak:Permasalahan banjir seringkali melanda wilayah DAS Kali Ngotok setiap tahun. Masalah banjir pada umumnya disebabkan oleh perubahan tata guna lahan dan penurunan fungsi sungai yang ada di wilayah DAS Kali Ngotok serta sering terjadinya back water dari sungai-sungai yang bermuara di Kali Brantas pada saat mengalami debit maksimal. Untuk itu studi perbandingan debit puncak banjir perlu dilakukan karena belum adanya penelitian mengenai pengendalian banjir. Sehingga dilakukan penelitian mengenai analisis model hidrograf satuan sintetik. Metode hidrograf satuan sintetik yang digunakan adalah SCS, Snyder, dan Nakayasu. Data hujan yang digunakan adalah data hujan tahun 1998-2016 dari 14 stasiun hujan di wilayah DAS Kali Ngotok. Metode poligon Thiessen digunakan untuk mengetahui besaran hujan yang tersebar di wilayah DAS Kali Ngotok. Besaran hujan rata-rata yang turun di DAS Kali Ngotok dalam kurun waktu 1998-2016 sebesar 97.05 mm. Pada tahap pemodelan, pembagian sub catchment DAS dilakukan dengan membagi menjadi 5 sub DAS. Hasil pemodelan dengan metode SCS, Snyder, dan Nakayasu menunjukkan besaran debit untuk kala ulang 2 tahun, 5 tahun, 10 tahun, 20 tahun, 25 tahun, 50 tahun, 100 tahun, dan 200 tahun yang bervariasi. Data AWLR yang mendekati hasil pemodelan adalah data tahun 2014. Hasil kalibrasi hidrograf untuk metode SCS dengan kala ulang 25 tahun sebesar 0.88, untuk metode Snyder dengan kala ulang 25 tahun sebesar 0.74, dan untuk metode Nakayasu dengan kala ulang 25 tahun sebesar 0.43 . Dengan demikian model hidrograf SCS dengan kala ulang 25 tahun mendekati dengan model hidrograf lapangan berdasarkan data AWLR yang ada serta sesuai dengan hasil pengamatan pada saat survey penduduk.
\end{abstract}

Kata-kata kunci: DAS, Kali Ngotok, SCS, Snyder, Nakayasu

Abstract: Flood problems often hit the Ngotok River watershed every year. The problem of flooding is generally caused by changes in land use and a decrease in river functions in the Ngotok River watershed area as well as frequent back water from rivers which empties into Brantas River when experiencing maximum discharge. For that reason a comparative study of peak flood discharge needs to be done because there is no research on flood control. So that research is conducted on the analysis of synthetic unit hydrograph models. The synthetic unit hydrograph method used is SCS, Snyder, and Nakayasu. Rainfall data used is data from 1998-2016 from 14 rain stations in the Ngotok River watershed. The Thiessen polygon method is used to determine the amount of rain scattered in the Ngotok River watershed. The average rainfall in the Ngotok River watershed in the period 1998-2016 was $97.05 \mathrm{~mm}$. In the modeling phase, the sub catchment division of the watershed is carried out by dividing it into 5 sub catchments. The modeling results using the SCS, Snyder, and Nakayasu methods show the amount of discharge for the return period of 2 years, 5 years, 10 years, 20 years, 25 years, 50 years, 100 years, and 200 years which varies. AWLR data approaching the modeling results are 2014 data. The hydrograph calibration results for the SCS method with a 25 year return period are 0.88 , for the Snyder method with a 25 year return period of 0.74, and for the Nakayasu method with a 25 year return period of 0.43. Thus the SCS hydrograph model with a 25 year return period approaches the field hydrograph model based on the AWLR data that exists and is in accordance with the observations during the population survey.

Keywords: Watershed, Ngotok River, SCS, Snyder, Nakayasu

Gilang Id'fi adalah Dosen Jurusan Teknik Sipil Fakultas Teknik UM; Jalan Semarang No.5 Malang 65145; E-mail: gilang.idfi@gmail.com 


\section{PENDAHULUAN}

Daerah aliran sungai (DAS) adalah suatu wilayah daratan yang secara topografik dibatasi oleh punggung-punggung gunung yang menampung dan menyimpan air hujan untuk kemudian menyalurkannya ke laut melalui sungai utama (Asdak, 2002). Perubahan tata guna lahan, topografi, jenis tanah, dan kelembaban tanah dapat mempengaruhi fungsi daerah aliran sungai (Hadisusanto, 2010). Selain itu intensitas curah hujan yang sering juga dapat mempengaruhi jumlah limpasan dan debit air sungai. Sehingga perhitungan debit puncak banjir perlu dilakukan untuk meminimalisir terjadinya banjir pada daerah aliran sungai.

Banjir pada DAS Kali Ngotok terjadi hampir setiap tahun pada saat musim penghujan. Adanya perubahan tata guna lahan dan penurunan fungsi sungai yang ada di wilayah DAS Kali Ngotok menyebabkan sering terjadi banjir. Dari dampak yang terjadi serta belum adanya penelitian mengenai pengendalian banjir, maka perlu dilakukan penelitian mengenai analisis model hidrograf satuan sintetik. Metode hidrograf satuan sintetik yang digunakan adalah SCS, Snyder, dan Nakayasu. Dengan menggunakan ketiga metode hidrograf satuan sintetik tersebut dapat dilihat perbandingan nilai debit puncak banjir yang terjadi pada DAS Kali Ngotok dengan membaca grafik hidrograf dari masing-masing metode. Penggunaan metode SCS, Snyder, dan Nakayasu bertujuan untuk mengetahui metode mana yang mendekati atau sesuai dengan karakterisitik DAS Kali Ngotok.

DAS Kali Ngotok ini secara administratif terletak di Kabupaten Mojokerto, Kota Mo- jokerto dan Kabupaten Jombang. Kali Ngotok adalah salah satu sungai yang berfungsi sebagai kolektor dari beberapa sungai seperti Kali Tembelang, Kali Sambong, Kali Jombang Kulon, Kali Jombang Wetan, Kali Bening, Kali Sewedang, Kali Gunting, Kali Balong, dan Kali Brangkal serta beberapa saluran pembuang (Idfi, 2017). Panjang Kali Ngotok kurang lebih 26,50 km dengan cakupan DAS yang meliputi areal seluas $\pm 722 \mathrm{~km}^{2}$. Secara geografis terletak pada 07 26'39' sampai dengan $07^{\circ} 32^{\prime}$ 19' Lintang Selatan serta 112 15' 47" sampai dengan $112^{\circ} 25^{\prime} 38^{\prime \prime}$ Bujur Timur.

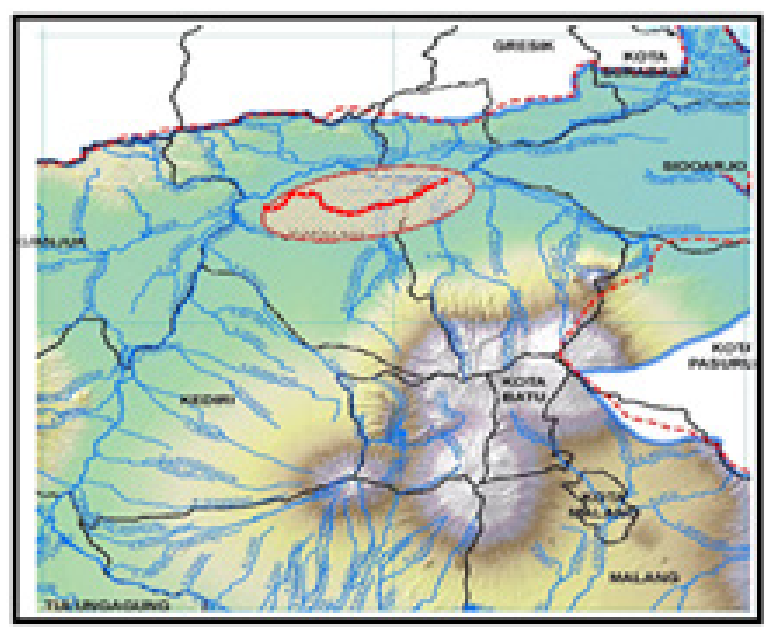

\section{Gambar 1. Lokasi Studi}

Manfaat dari penelitian ini diharapkan dapat membantu pemerintah dalam upaya pengendalian banjir. Dengan adanya penelitian ini dapat diketahui debit puncak banjir di DAS Kali Ngotok. Sedangkan bagi peneliti, hasil penelitian ini diharapkan dapat menambah kontribusi bagi peneliti dan dapat menjadi rujukan penelitian selanjutnya.

\section{METODE}

Metode yang digunakan pada penelitian ini adalah sebagai berikut: 


\section{a. Diagram Alir Penelitian}

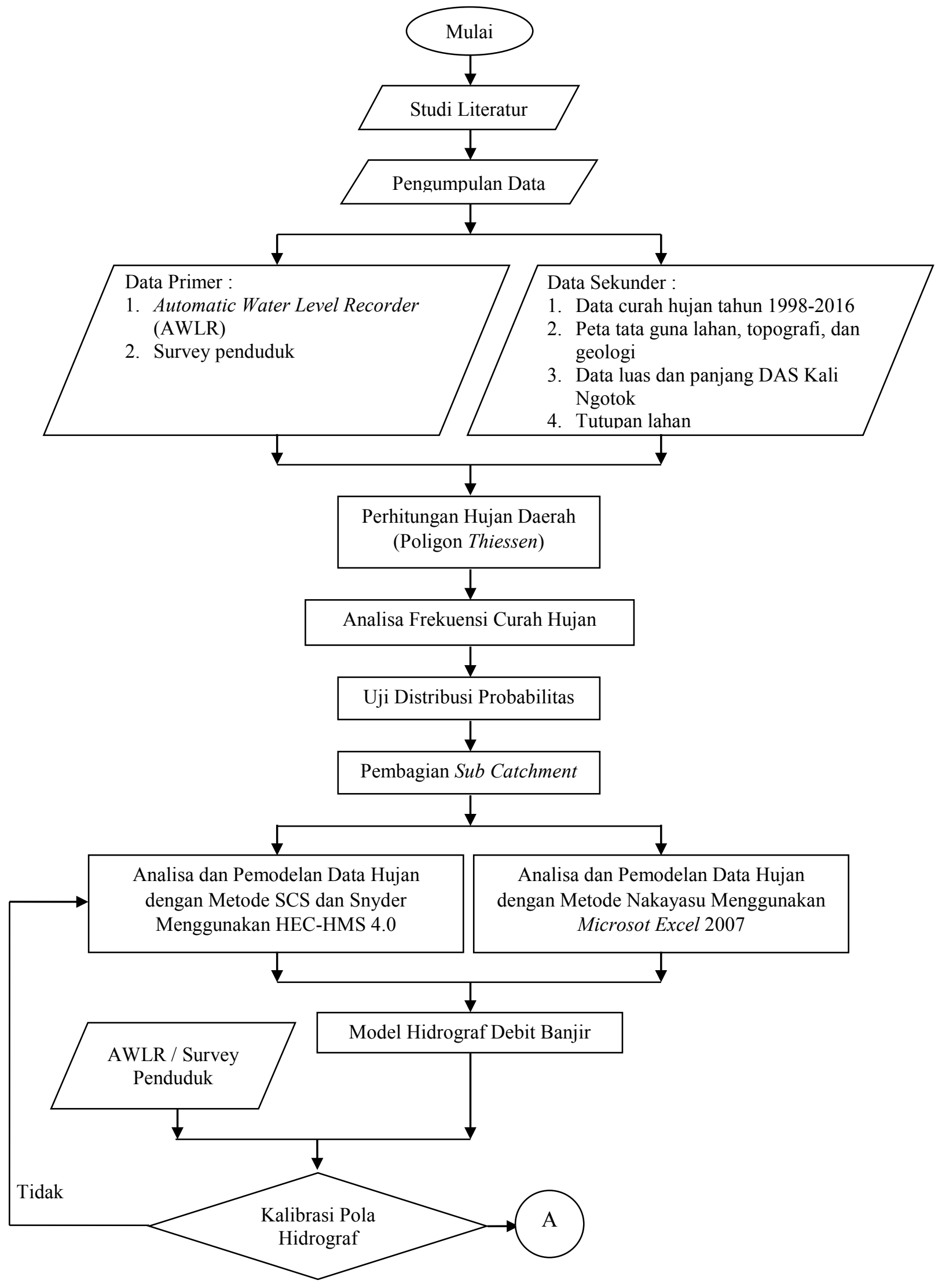




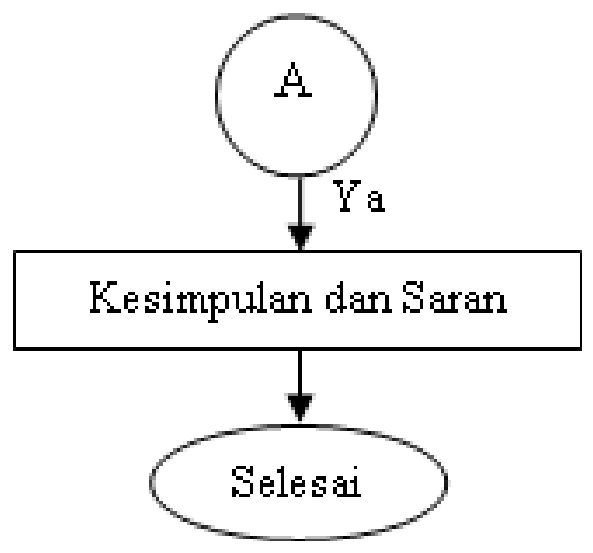

\section{Gambar 2. Diagram Alir Penelitian}

\section{b. Pengumpulan Data}

Data yang digunakan diperoleh dari data primer yaitu Automatic Water Level Recorder (AWLR) dan survey penduduk, serta data sekunder berupa data data curah hujan tahun 1998-2016, peta tataguna lahan, topografi, geologi, data luas dan panjang DAS Kali Ngotok, dan tutupan lahan.

\section{c. Analisis Data Curah Hujan}

Data hujan yang diperoleh adalah merupakan data hujan titik, agar dapat digunakan untuk perhitungan selanjutnya maka hujan titik harus dirubah menjadi hujan daerah dengan membuat Poligon Thiesen. Agar diperoleh distribusi frekuensi terbaik maka data yang ada, sebelumnya dianalisis dahulu dengan 4 macam metode distribusi probabilitas yaitu Gumbel, Normal, Log Normal, dan Log Pearson Tipe III. Uji distribusi probabilitas dengan menggunakan 2 metode yaitu, metode Chi Kuadrat dan Metode SmirnovKolmogorof. Pembagian sub catchment DAS menjadi 5 sub DAS dilakukan sebelum tahap pemodelan. Kemudian melakukan pemodelan data hujan dengan metode SCS, Snyder, dan Nakayasu menggunakan software HEC-HMS 4.0 dan Microsoft Excel 2007.

\section{d. Parameter Input Pemodelan}

Sebelum melakukan pemodelan dengan software HEC-HMS 4.0, terdapat be- berapa parameter yang harus dihitung terlebih dahulu. Parameter-parameter yang dihitung mempengaruhi hasil output dari pemodelan metode SCS dan Snyder. Parameter yang dihitung adalah curve number $(\mathrm{CN})$, impervious area, initial abstraction, kemiringan DAS, kemiringan sungai, dan time lag untuk masing-masing sub DAS.

\section{e. Validasi}

Kalibrasi model dapat dilakukan dengan cara membandingkan hidrograf pemodelan dengan hidrograf hasil pengamatan. Menurut Nash \& Sutcliffe (1970), adapun metode untuk menentukan kriteria kalibrasi model terhadap hasil pengamatan dilapangan sebagai berikut:

$$
E I=1-\frac{\sum_{i=1}^{n}\left(\mathrm{Q}_{o}-Q_{s}\right)^{2}}{\sum_{i=1}^{n}\left(Q_{o}-Q_{a}\right)^{2}}
$$

Dengan :

$$
\begin{array}{ll}
\text { EI } & =\text { indek efisiensi } \\
\text { Qo } & =\text { debit pengukuran (observasi) } \\
\text { Qs } & =\text { Debit simulasi } \\
\text { Qa } & =\text { debit rata-rata pengukuran }
\end{array}
$$

Besarnya nilai EI menurut metode Nash terbagi dalam tiga kategori yaitu: tingkat akurasi rendah jika $\mathrm{EI} \leq 0,50$, tingkat akurasi sedang jika $0,50<$ EI $<0,70$, dan tingkat akurasi tinggi jika $\mathrm{EI} \geq 0,70$. 


\section{PEMBAHASAN}

\section{a. Analisa Data Hujan}

Data curah hujan yang digunakan adalah data hujan tahun 1998-2016. Dari hasil perhitungan didapatkan curah hujan rata-rata sebesar $97.05 \mathrm{~mm}$. Besaran untuk masing-masing tahun disajikan dalam tabel 1 di bawah ini.

Tabel 1. Curah Hujan Rata-Rata DAS Kali
Ngotok
\begin{tabular}{cccc}
\hline Tahun & $\begin{array}{c}\text { Curah Hu- } \\
\text { jan (mm) }\end{array}$ & Tahun & $\begin{array}{c}\text { Curah Hujan } \\
\text { (mm) }\end{array}$ \\
\hline 1998 & 84.34 & 2008 & 76.33 \\
\hline 1999 & 85.52 & 2009 & 85.34 \\
\hline 2000 & 119.82 & 2010 & 100.15 \\
\hline 2001 & 98.58 & 2011 & 101.82 \\
\hline 2002 & 90.16 & 2012 & 109.26 \\
\hline 2003 & 105.31 & 2013 & 115.43 \\
\hline 2004 & 120.39 & 2014 & 85.26 \\
\hline 2005 & 80.73 & 2015 & 87.61 \\
\hline 2006 & 82.02 & 2016 & 119.94 \\
\hline 2007 & 95.94 & & \\
\hline
\end{tabular}

\section{b. Hujan Periode Ulang}

Dari hasil perhitungan curah hujan rencana dengan metode Log Pearson Tipe III didapatkan nilai besaran hujan berdasarkan periode ulang hujan.

\begin{tabular}{cc}
\multicolumn{2}{l}{ Tabel 2. Perhitungan Curah Hujan Rencana } \\
\hline Periode Ulang (tahun) & Xt ( mm) \\
\hline 2 & 95.44 \\
\hline 5 & 108.518 \\
\hline 10 & 116.476 \\
\hline 20 & 124.33 \\
\hline 25 & 125.964 \\
\hline 50 & 132.706 \\
\hline 100 & 139.22 \\
\hline 200 & 145.593 \\
\hline
\end{tabular}

\section{c. Pembagian Sub Catchment DAS}

Sub catchment DAS dibagi menjadi 5 bagian berdasarkan topografi dan sungai-sungai penyusunnya. Dilihat pada tabel 3 berikut.
Tabel 3. Pembagian Sub Catchment DAS

\begin{tabular}{|c|c|c|}
\hline Sub DAS & Nama Sungai & $\begin{array}{c}\text { Luas DAS } \\
\qquad\left(\mathbf{k m}^{2}\right)\end{array}$ \\
\hline \multirow{4}{*}{1} & Tembelang & \multirow{4}{*}{127.854} \\
\hline & Sambong & \\
\hline & Jombang Kulon & \\
\hline & Jombang Wetan & \\
\hline \multirow{3}{*}{2} & Bening & \multirow{3}{*}{112.954} \\
\hline & Trawasan & \\
\hline & Sal. Drainase Sebani & \\
\hline 3 & Gunting & 241.159 \\
\hline \multirow{3}{*}{4} & Balong & \multirow{3}{*}{44.85} \\
\hline & Panemon & \\
\hline & $\begin{array}{l}\text { Sal. Drainase Prajurit } \\
\text { Kulon }\end{array}$ & \\
\hline 5 & Brangkal & 195.182 \\
\hline
\end{tabular}

\section{d. Perhitungan Parameter Input Pemod-} elan

Perhitungan Parameter dapat dilihat mulai tabel 4 s.d tabel 9 sebagai berikut:

Tabel 4. Curve Number (CN)

\begin{tabular}{cc}
\hline Sub DAS & CN \\
\hline 1 & 80.75 \\
\hline 2 & 79.67 \\
\hline 3 & 79.44 \\
\hline 4 & 80.49 \\
\hline 5 & 79.04 \\
\hline
\end{tabular}

Tabel 5. Impervious Area

\begin{tabular}{cc}
\hline Sub DAS & Impervious (\%) \\
\hline 1 & 10.1 \\
\hline 2 & 8.83 \\
\hline 3 & 8.55 \\
\hline 4 & 14.45 \\
\hline 5 & 6.77 \\
\hline
\end{tabular}

Tabel 6. Initial Abstraction

\begin{tabular}{cc}
\hline Sub DAS & Initial Abstraction \\
\hline 1 & 0.477 \\
\hline 2 & 0.511 \\
\hline 3 & 0.518 \\
\hline 4 & 0.485 \\
\hline 5 & 0.53 \\
\hline
\end{tabular}


Tabel 7. Kemiringan DAS

\begin{tabular}{cc}
\hline Sub DAS & Kemiringan DAS (\%) \\
\hline 1 & 4.5 \\
\hline 2 & 3.96 \\
\hline 3 & 3.82 \\
\hline 4 & 4.3 \\
\hline 5 & 4.64 \\
\hline
\end{tabular}

Tabel 8. Kemiringan Sungai

\begin{tabular}{cc}
\hline Sub DAS & Kemiringan DAS (\%) \\
\hline 1 & 6.59 \\
\hline 2 & 5.83 \\
\hline 3 & 5.08 \\
\hline 4 & 6.26 \\
\hline 5 & 5.33 \\
\hline
\end{tabular}

Tabel 9. Time Lag

\begin{tabular}{ccrrc}
\hline \multirow{2}{*}{$\begin{array}{c}\text { Sub } \\
\text { DAS }\end{array}$} & \multicolumn{2}{c}{ Time Lag DAS } & \multicolumn{2}{c}{ Time Lag Sungai } \\
\cline { 2 - 5 } & Jam & Menit & Jam & Menit \\
\hline 1 & 8.872 & 532.338 & 15.811 & 948.679 \\
\hline 2 & 8.532 & 511.892 & 17.457 & 1047.39 \\
\hline 3 & 11.198 & 671.894 & 26.794 & 1607.615 \\
\hline 4 & 4.667 & 280.009 & 13.758 & 825.508 \\
\hline 5 & 9.477 & 568.602 & 24.002 & 1440.141 \\
\hline
\end{tabular}

\section{e. Model Hidrograf Banjir}

\section{Metode SCS}

Dari hasil komputasi didapatkan hasil akhir berupa grafik model hidrograf serta data debit puncak banjir yang terjadi berdasarkan kala ulang tertentu pada masing-masing sub DAS dapat dilihat pada tabel 10 dangambar 3 berikut:

Tabel 10. Rekapitulasi Hasil Pemodelan Metode SCS

\begin{tabular}{|c|c|c|c|c|c|c|c|c|c|c|}
\hline \multirow{3}{*}{$\begin{array}{c}\text { Kala } \\
\text { Ulang } \\
\text { (Ta- } \\
\text { hun) }\end{array}$} & \multicolumn{2}{|c|}{ Sub DAS 1} & \multicolumn{2}{|c|}{ Sub DAS 2} & \multicolumn{2}{|c|}{ Sub DAS 3} & \multicolumn{2}{|c|}{ Sub DAS 4} & \multicolumn{2}{|c|}{ Sub DAS 5} \\
\hline & $\begin{array}{l}\text { Lama } \\
\text { Banjir }\end{array}$ & $\begin{array}{c}\text { Debit } \\
\text { Pun- } \\
\text { cak }\end{array}$ & $\begin{array}{l}\text { Lama } \\
\text { Banjir }\end{array}$ & $\begin{array}{c}\text { Debit } \\
\text { Pun- } \\
\text { cak }\end{array}$ & $\begin{array}{l}\text { Lama } \\
\text { Banjir }\end{array}$ & $\begin{array}{c}\text { Debit } \\
\text { Pun- } \\
\text { cak }\end{array}$ & $\begin{array}{l}\text { Lama } \\
\text { Banjir }\end{array}$ & $\begin{array}{c}\text { Debit } \\
\text { Pun- } \\
\text { cak }\end{array}$ & $\begin{array}{l}\text { Lama } \\
\text { Banjir }\end{array}$ & $\begin{array}{c}\text { Debit } \\
\text { Pun- } \\
\text { cak }\end{array}$ \\
\hline & (jam) & $\begin{array}{c}\left(\mathrm{m}^{3} /\right. \\
\text { detik) }\end{array}$ & (jam) & $\begin{array}{c}\left(\mathbf{m}^{3} /\right. \\
\text { detik) }\end{array}$ & (jam) & $\begin{array}{c}\left(\mathbf{m}^{3} /\right. \\
\text { detik) }\end{array}$ & (jam) & $\begin{array}{c}\left(\mathrm{m}^{3} /\right. \\
\text { detik })\end{array}$ & (jam) & $\begin{array}{c}\left(\mathrm{m}^{3} /\right. \\
\text { detik) }\end{array}$ \\
\hline 2 & 64 & 124.2 & 62 & 108.1 & 68 & 196.4 & 44 & 63.9 & 67 & 172.1 \\
\hline 5 & 64 & 147.6 & 62 & 129.9 & 68 & 233.9 & 44 & 75.9 & 68 & 205.6 \\
\hline 10 & 64 & 162.1 & 63 & 142.8 & 68 & 257.2 & 44 & 83.3 & 68 & 226.5 \\
\hline 20 & 64 & 176.6 & 63 & 155.8 & 68 & 280.4 & 45 & 90.7 & 68 & 247.3 \\
\hline
\end{tabular}

\begin{tabular}{|c|c|c|c|c|c|c|c|c|c|c|}
\hline \multirow{3}{*}{$\begin{array}{c}\text { Kala } \\
\text { Ulang } \\
\text { (Ta- } \\
\text { hun) }\end{array}$} & \multicolumn{2}{|c|}{ Sub DAS 1} & \multicolumn{2}{|c|}{ Sub DAS 2} & \multicolumn{2}{|c|}{ Sub DAS 3} & \multicolumn{2}{|c|}{ Sub DAS 4} & \multicolumn{2}{|c|}{ Sub DAS 5} \\
\hline & $\begin{array}{l}\text { Lama } \\
\text { Banjir }\end{array}$ & $\begin{array}{c}\text { Debit } \\
\text { Pun- } \\
\text { cak }\end{array}$ & $\begin{array}{l}\text { Lama } \\
\text { Banjir }\end{array}$ & $\begin{array}{c}\text { Debit } \\
\text { Pun- } \\
\text { cak }\end{array}$ & $\begin{array}{l}\text { Lama } \\
\text { Banjir }\end{array}$ & $\begin{array}{c}\text { Debit } \\
\text { Pun- } \\
\text { cak }\end{array}$ & $\begin{array}{l}\text { Lama } \\
\text { Banjir }\end{array}$ & $\begin{array}{c}\text { Debit } \\
\text { Pun- } \\
\text { cak }\end{array}$ & $\begin{array}{l}\text { Lama } \\
\text { Banjir }\end{array}$ & $\begin{array}{c}\text { Debit } \\
\text { Pun- } \\
\text { cak }\end{array}$ \\
\hline & (jam) & $\begin{array}{c}\left(\mathrm{m}^{3} /\right. \\
\text { detik) }\end{array}$ & (jam) & $\begin{array}{c}\left(\mathrm{m}^{3} /\right. \\
\text { detik }) \\
\end{array}$ & (jam) & $\begin{array}{c}\left(\mathrm{m}^{3} /\right. \\
\text { detik) }\end{array}$ & (jam) & $\begin{array}{c}\left(\mathrm{m}^{3} /\right. \\
\text { detik) }\end{array}$ & (jam) & $\begin{array}{c}\left(\mathrm{m}^{3} /\right. \\
\text { detik) }\end{array}$ \\
\hline 25 & 64 & 179.7 & 63 & 158.5 & 68 & 285.3 & 45 & 92.3 & 68 & 251.7 \\
\hline 50 & 65 & 192.2 & 63 & 169.7 & 68 & 305.5 & 45 & 98.7 & 68 & 269.8 \\
\hline 100 & 66 & 204.5 & 63 & 180.7 & 69 & 325.2 & 45 & 105 & 68 & 287.4 \\
\hline 200 & 66 & 216.5 & 63 & 191.5 & 69 & 344.5 & 45 & 111.1 & 68 & 304.8 \\
\hline
\end{tabular}




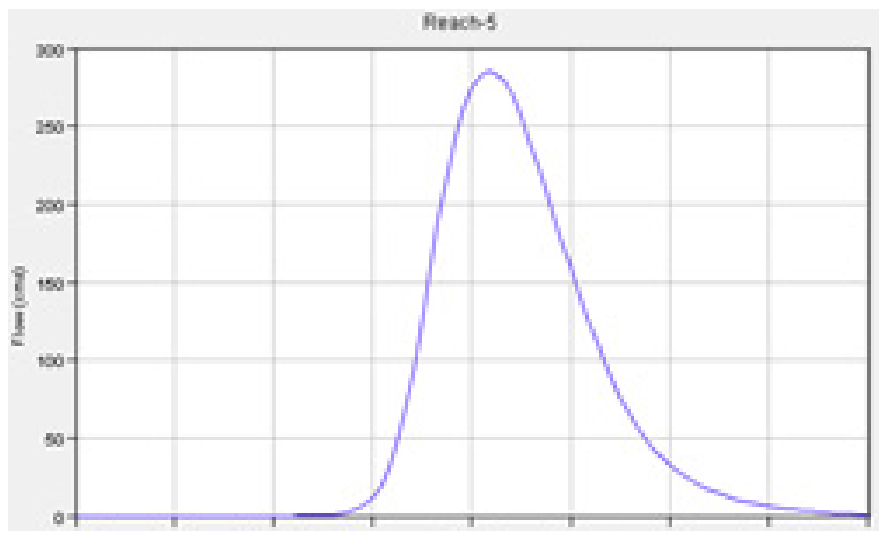

\section{Gambar 3. Grafik Hidrograf SCS Kala Ulang 25 Tahun Sub DAS}

\section{Metode SCS}

Dari hasil komputasi didapatkan hasil akhir berupa grafik model hidrograf serta data debit puncak banjir yang terjadi berdasarkan kala ulang tertentu pada masing-masing sub DAS dapat dilihat pada table dan gambar berikut :

Tabel 11. Rekapitulasi Hasil Pemodelan Metode Snyder

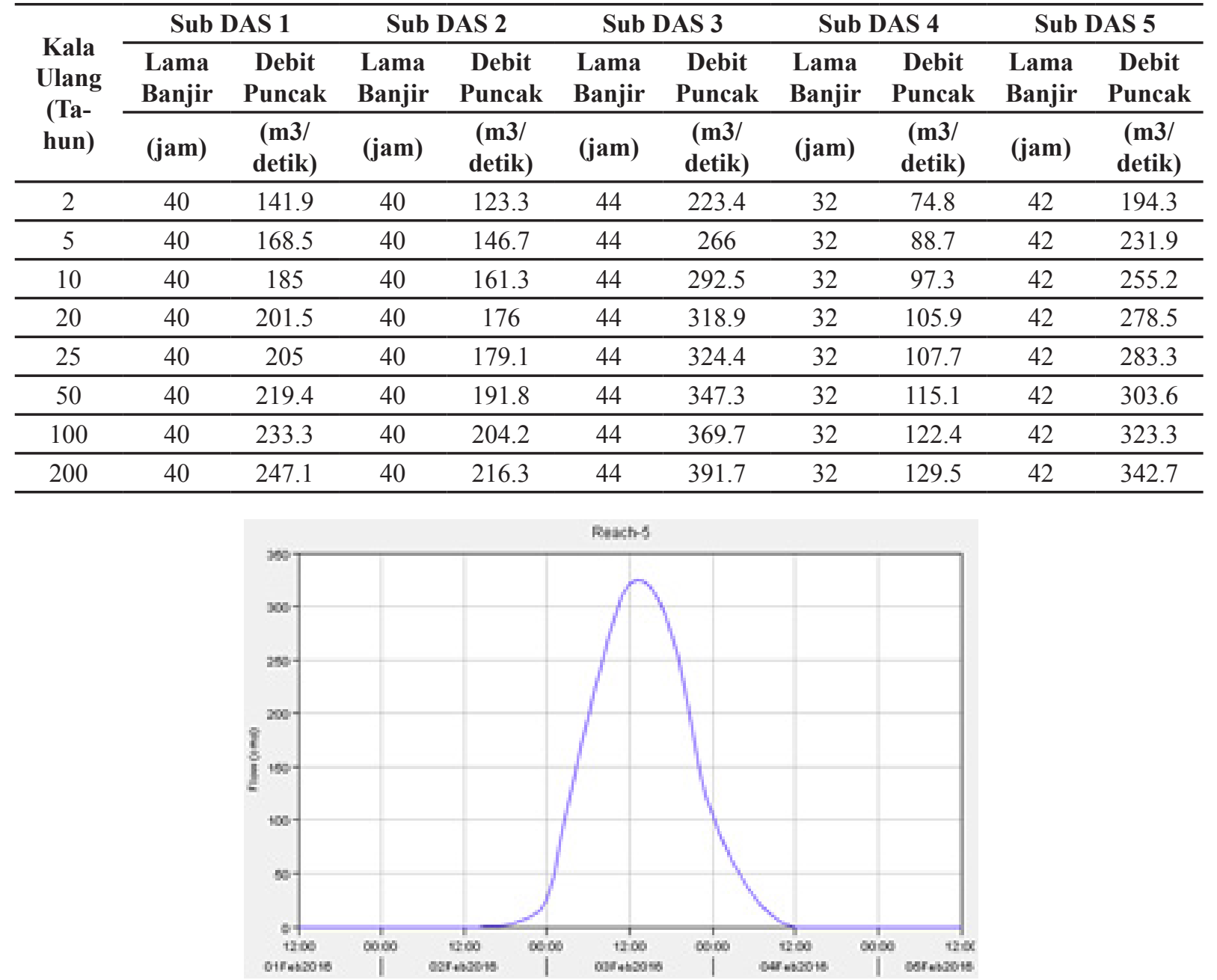

Gambar 4. Grafik Hidrograf Snyder Kala Ulang 25 Tahun Sub DAS 3 


\section{Metode Nakayasu}

Dari hasil komputasi didapatkan hasil akhir berupa grafik model hidrograf serta data debit puncak banjir yang terjadi berdasarkan kala ulang tertentu pada masing-masin sub DAS dapat dilihat pada table dan gambar berikut :

Tabel 12. Rekapitulasi Hasil Pemodelan Metode Nakayasu

\begin{tabular}{|c|c|c|c|c|c|c|c|c|c|c|}
\hline \multirow{3}{*}{$\begin{array}{c}\text { Kala } \\
\text { Ulang } \\
\text { (Tahun) }\end{array}$} & \multicolumn{2}{|c|}{ Sub DAS 1} & \multicolumn{2}{|c|}{ Sub DAS 2} & \multicolumn{2}{|c|}{ Sub DAS 3} & \multicolumn{2}{|c|}{ Sub DAS 4} & \multicolumn{2}{|c|}{ Sub DAS 5} \\
\hline & $\begin{array}{l}\text { Lama } \\
\text { Banjir }\end{array}$ & $\begin{array}{c}\text { Debit } \\
\text { Puncak }\end{array}$ & $\begin{array}{l}\text { Lama } \\
\text { Banjir }\end{array}$ & $\begin{array}{c}\text { Debit } \\
\text { Puncak }\end{array}$ & $\begin{array}{l}\text { Lama } \\
\text { Banjir }\end{array}$ & $\begin{array}{c}\text { Debit } \\
\text { Puncak }\end{array}$ & $\begin{array}{l}\text { Lama } \\
\text { Banjir }\end{array}$ & $\begin{array}{l}\text { Debit Pun- } \\
\text { cak }\end{array}$ & $\begin{array}{c}\text { Lama } \\
\text { Banjir }\end{array}$ & $\begin{array}{c}\text { Debit } \\
\text { Puncak }\end{array}$ \\
\hline & (jam) & $\begin{array}{c}\text { (m3/de- } \\
\text { tik) }\end{array}$ & (jam) & (m3/detik) & (jam) & $\begin{array}{c}\text { (m3/de- } \\
\text { tik) }\end{array}$ & (jam) & (m3/detik) & (jam) & $\begin{array}{c}\text { (m3/de- } \\
\text { tik) }\end{array}$ \\
\hline 2 & 86 & 194.9 & 88 & 168.6 & 96 & 255.1 & 68 & 74.9 & 96 & 226.9 \\
\hline 5 & 88 & 239.1 & 90 & 206.8 & 96 & 313.2 & 69 & 92 & 96 & 278.4 \\
\hline 10 & 89 & 266.6 & 91 & 230.5 & 96 & 349.1 & 70 & 102.5 & 96 & 310.4 \\
\hline 20 & 90 & 293.9 & 92 & 254.2 & 96 & 385.1 & 71 & 113 & 96 & 342.3 \\
\hline 25 & 90 & 299.7 & 92 & 259.1 & 96 & 392.6 & 71 & 115.3 & 96 & 348.9 \\
\hline 50 & 91 & 323.5 & 93 & 279.7 & 96 & 423.9 & 71 & 124.4 & 96 & 376.7 \\
\hline 100 & 91 & 346.6 & 93 & 299.7 & 96 & 454.3 & 72 & 133.3 & 96 & 403.7 \\
\hline 200 & 92 & 369.5 & 94 & 319.5 & 96 & 484.3 & 72 & 142.1 & 97 & 430.3 \\
\hline
\end{tabular}

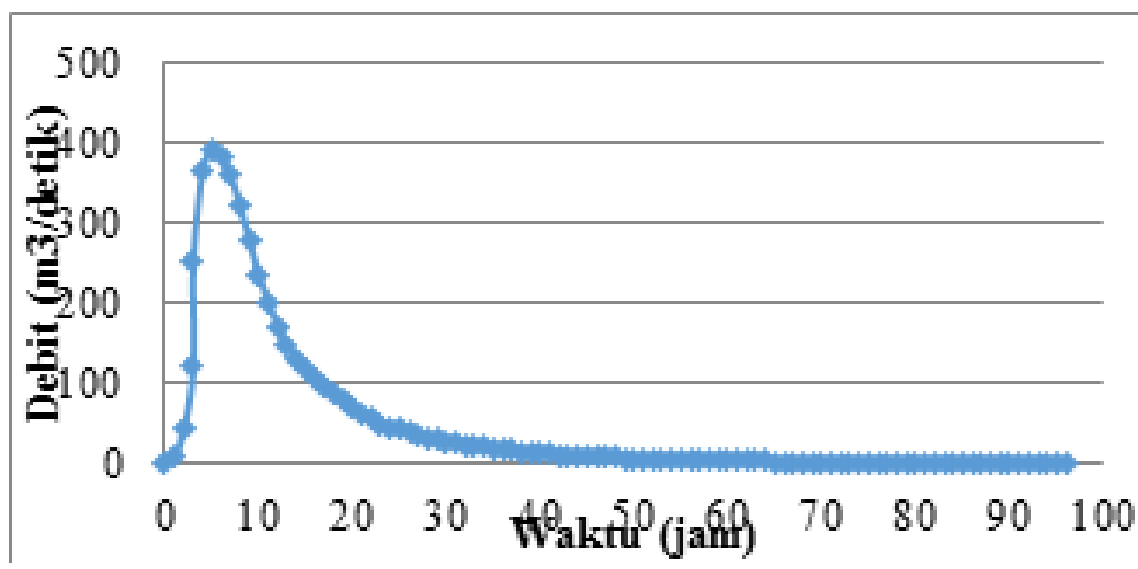

Gambar 5. Grafik Hidrograf Nakayasu Kala Ulang 25 Tahun Sub DAS 3

\section{f. Perbandingan Hidrograf}

Hasil perbandingan model hidrograf dengan metode SCS. Snyder dan Nakayasu dapat dilihat pada gambar berikut :

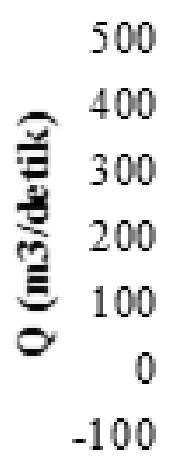

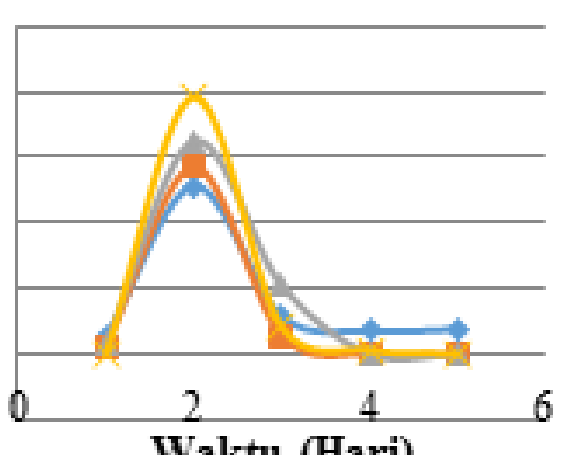

Waktu (Hari)

Gambar 6. Grafik Perbandingan Model Hidrograf 


\section{g. Validasi model hidrograf}

Dari hasil perhitungan menggunakan rumus Nash didapat nilai kalibrasi sebesar 0.88 untuk model SCS, untuk model Snyder didapatkan angka validasi sebesar 0.74 sedangkan untuk model Nakayasu didapatkan angka sebesar 0.43

\section{SIMPULAN}

Berdasarkan rumusan masalah serta hasil dan pembahasan yang telah dipaparkan sebelumnya, maka dapat disimpulkan bahwa model hidrograf yang terjadi di DAS Kali Ngotok dengan metode SCS, Snyder, dan Nakayasu dengan kala ulang tertentu cukup bervariasi dengan lama waktu banjir dan debit banjir yang terjadi. Semakin luas cakupan sub DAS dan semakin lama periode ulang yang dihitung, semakin lama waktu banjir dan semakin besar pula debit banjir yang terjadi.

Model hidrograf yang terjadi bila dibandingkan atau dikalibrasi dengan model hidrograf lapangan cukup signifikan. Untuk metode SCS dengan kala ulang 25 tahun, kesesuaian kalibrasi mempunyai tingkat akurasi tinggi sebesar 0.88. Untuk metode Snyder dengan kala ulang 25 tahun, kesesuaian kalibrasi mempunyai tingkat akurasi tinggi sebesar 0.74 . Sedangkan untuk metode Nakayasu dengan kala ulang 25 tahun, kesesuaian kalibrasi mempunyai tingkat akurasi rendah sebesar 0.43.

Model yang mendekati kondisi eksisting atau lapangan berdasarkan data kalibrasi yang ada adalah model dengan metode SCS dengan kala ulang 25 tahun. Metode SCS kala ulang 25 tahun menghasilkan debit puncak sebesar $285.30 \mathrm{~m} 3 /$ detik dan debit puncak lapangan sebesar 255.99 m3/detik.

\section{DAFTAR RUJUKAN}

Asdak, Chay. 2002. Hidrologi dan Pen gelolaan Daerah Aliran Sungai. Yog yakarta: Gadjah Mada University Press.

Budiawan, S, S. 2012. Pendugaan Debit Pun cakMenggunakanModelRasionalDanSCSCN (Soil Conservation Service Curve Num ber). Departemen Manajemen Hutan Fakultas Kehutanan Institut Pertanian Bo gor. Jakarta

Harto, Sri. 1993. Analisis Hidrologi. Jakarta: Gramedia Pustaka Utama

Hadisusanto. 2010. Aplikasi Hidrologi. Malang: Jogja Mediautama.

Hanova, Y,2018, Analisis Potensi Lim pasan Permukaan (Run Off) Di Ka wasan Industri Medan Menggunakan Metode SCS. Jurnal tidak diterbitkan. Jurusan Teknik Sipil Fakultas Teknik Sipil dan Perencanaan Institut Teknologi Medan Idfi, Gilang. 2017. Perbandingan Mod el Aliran Banjir Unsteady Flow dan Steady Flow Pada Sungai Ngotok Ring Kanal. Jurnal Bangunan, 22(2), 31-40. Nash JE, Sutcliffe JV. 1970. River Flow Forecasting Through Conceptual Models. J.Hydrol. 101: 282-290.

Pratiwi, Dimas Tiara. 2011. Analisis Hidrograf Aliran Menggunakan HEC-HMS (Studi Ka sus : DAS Citarum Hulu). Jurnal tidak diter bitkan. FMIPA : Institut Pertanian Bogor. Bogor.

Soemarto, C.D. 1987. Hidrologi Teknik. Sura baya : Usaha Nasional.

Soewarno. 1995. Hidrologi Aplikasi Metode Statistik Untuk Analisa Data. Bandung: Penerbit Nova. 
10 JURNAL BANGUNAN, VOL. 25, NO.2, OKTOBER 2020: 1-10 